\title{
Recombinant human soluble thrombomodulin ameliorates acetaminophen-induced liver toxicity in mice
}

\author{
AKIFUMI KUWANO $^{1}$, MOTOYUKI KOHJIMA ${ }^{1}$, HIDEO SUZUKI ${ }^{1}$, AKIHIRO YAMASAKI $^{1}$, TOMOKO OHASHI ${ }^{1}$, \\ KOJI IMOTO ${ }^{1}$, MIHO KUROKAWA ${ }^{1}$, YUSUKE MORITA ${ }^{1}$, MASAKI KATO $^{1}$ and YOSHIHIRO OGAWA $^{1-3}$ \\ ${ }^{1}$ Department of Medicine and Bioregulatory Science, Graduate School of Medical Sciences, \\ Kyushu University, Fukuoka 812-8582; ${ }^{2}$ Department of Molecular and Cellular Metabolism, \\ Graduate School of Medical and Dental Sciences, Tokyo Medical and Dental University, Tokyo 113-8510; \\ ${ }^{3}$ CREST, Japan Agency for Medical Research and Development, Tokyo 100-0004, Japan
}

Received October 9, 2018; Accepted May 21, 2019

DOI: $10.3892 /$ etm.2019.7665

\begin{abstract}
Recombinant human soluble thrombomodulin alpha (rhTM) has been developed as an anticoagulant with anti-inflammatory activity. Notably, acetaminophen (APAP) -induced liver disease (AILI) is caused by direct metabolite-induced hepatotoxicity as well as hepatic hyper-coagulation. To evaluate the utility of anticoagulant for the treatment of AILI, rhTM was administered in a mouse AILI model and liver damage was analyzed. AILI was induced in 8-week-old mice by intraperitoneal injection of APAP. rhTM $(20 \mathrm{mg} / \mathrm{kg})$ or placebo was injected at the same time as APAP administration. Serum alanine aminotransferase, fibrin degradation products and high-mobility group box 1 levels were significantly decreased in the rhTM-treated group compared with the control group. Furthermore, rhTM reduced the necrotic area and fibrin deposition in liver sections. rhTM suppressed the mRNA expression of heme oxygenase-1, plasminogen activator inhibitor type-1, tissue factors, and inflammatory cytokines compared with the control group. rhTM did not change the hepatic GSH content at $2 \mathrm{~h}$ after APAP injection, but restored them at $4 \mathrm{~h}$ after the insult. rhTM ameliorated liver damage in mice with AILI, probably via the improvement in liver perfusion induced by it's anticoagulant acitivity, which can lead to the suppression of secondary liver damage.
\end{abstract}

\section{Introduction}

In some patients with liver injury, the liver disease proceeds to acute liver failure (ALF), a life-threatening systemic

Correspondence to: Dr Masaki Kato, Department of Medicine and Bioregulatory Science, Graduate School of Medical Sciences, Kyushu University, 3-1-1 Maidashi, Higashi-ku, Fukuoka 812-8582, Japan

E-mail: mkato11@intmed3.med.kyushu-u.ac.jp

Key words: acute liver failure, acetaminophen, anticoagulant, coagulopathy, thrombomodulin disorder characterized with severe coagulopathy and encephalopathy (1). Currently, the only effective therapy for ALF is liver transplantation (2,3). Difficulties associated with the development of effective treatments for ALF may be attributed to the incomplete understanding of the mechanisms involved in disease progression.

Intrahepatic microcirculatory disturbance is thought to play a key role in the progression of ALF (4). Hepatic microcirculatory perfusion failure is a determinant of liver dysfunction in warm ischemia-reperfusion (5). Increased fibrinogen catabolism and low platelet counts in ALF patients were consistent with the involvement of hepatic hyper-coagulation (6). Sinusoidal fibrin deposition in ALF livers in patients and experimental models may support the presence of intrahepatic coagulopathy, probably associated with disturbed sinusoidal flow (6-9). Hemodynamic study in ALF patients showed that blood inflow from portal vein was mostly excreted directly into hepatic vein, suggesting impaired parenchymal perfusion (10). Collectively, treatments to improve the hepatic hyper-coagulation may be useful to attenuate liver damage in ALF; however, suitable anticoagulant to treat ALF have not been established $(11,12)$.

Acetaminophen (APAP) is a widely used analgesic/antipyretic drug with few side effects at therapeutic doses (13). It is well known that overdose of APAP causes liver injury via its metabolite $\mathrm{N}$-acetyl-p-benzoquinone imine (NAPQI) that induces direct hepatocyte necrosis by oxidative stress and mitochondrial dysfunction (14-16). N-acetyl cysteine (NAC) is a useful antidote for APAP induced liver injury (AILI) via replenishing intracellular glutathione (GSH), however, delayed administration of NAC diminished its efficacy (17-20). In addition, hepatic hyper-coagulation seems to be involved in the pathogenesis of AILI (21). Tissue-factor (TF) dependent activation of coagulatory system, elevated concentration of PAI-1, and liver fibrin depositions suggested the disturbance in local liver perfusion (22).

Thrombomodulin (TM) is a thrombin receptor expressed on the surface of endothelial cells and plays a crucial role in regulating the coagulation cascades via anticoagulant activity by inhibiting thrombin and accelerating activated protein $\mathrm{C}$ (APC) activity (23-25). In addition, TM binds and neutralizes 
high-mobility group box 1 (HMGB1) released from necrotic cells, dampening the inflammatory responses (26-28). These features of TM have allowed the development of recombinant soluble human TM alpha (rhTM) as an anticoagulant with low frequency of hemorrhagic complications (29) and to treat disseminated intravascular coagulation (DIC) with inflammatory reactions, such as sepsis (30).

The features of TM tempted us to evaluate its utility to treat acute liver injury accompanied with hepatic hyper-coagulation. We administrated rhTM into a mouse model of AILI and analyzed the efficacy to suppress liver damage.

\section{Materials and methods}

Chemicals. APAP was purchased from Sigma (St. Louis, MO). rhTM was purchased from Asahi Kasei Pharma Co. Ltd. (Tokyo, Japan).

Animals. Eight-week-old male C57BL/6J mice weighing 20-25 g were obtained from Japan SLC (Shizuoka, Japan). Mice were maintained under controlled conditions with free access to standard chow and water. All studies were performed in accordance with the Guide for the Care and Use of Laboratory Animals (National Institutes of Health) and approved by the Animal Care Committee of Kyushu University. Totally 140 mice were used in this study. All mice were fasted for $16 \mathrm{~h}$ before the experiments but allowed water ad libitum. The weight of the animals at the time of sacrifice was $18-22 \mathrm{~g}$. APAP $(200 \mathrm{mg} / \mathrm{kg}$ body weight) dissolved in phosphate-buffered solution (PBS) was injected intraperitoneally. At the same time as APAP injection, rhTM (20 mg/kg body weight) dissolved in saline was injected intraperitoneally (TM group). The dose of $\mathrm{rh}^{\mathrm{TM}}$ was chosen with reference to the previous reports (31-34) and our preliminary experiments. Control animals underwent sham injections with saline (control group). The mice in control and TM groups were sacrificed at $0,2,4,24$ and $48 \mathrm{~h}$ ( $\mathrm{n}=10$ at each time point/group) in this study. All amimals were euthanized by sevoflurane at concentrations of $4-5 \%$ for induction and 2-3\% for maintenance, as described previously $(35,36)$. The depth of anesthesia was confirmed by loss of the postural reaction and righting reflex (the pedal withdrawal reflex in the forelimbs and hind limbs, the tail pinch reflex, and the eyelid reflex). Blood samples were drawn from tail vein or inferior vena cava and the livers were collected. Approximately 700-1,200 $\mu \mathrm{l}$ of blood was extracted by exsanguination. A combination of lack of pulse, breathing, corneal reflex, and presence of rigor morits was used to confirm death. The blood samples were centrifuged for $15 \mathrm{~min}$ at 3,000 rpm $(1,500 \times \mathrm{g})$ at $4^{\circ} \mathrm{C}$, and serum samples were collected and stored at $-80^{\circ} \mathrm{C}$. For RNA isolation, liver samples were snap-frozen in liquid nitrogen and stored at $-80^{\circ} \mathrm{C}$.

To evaluate hepatic glutathione (GSH) contents, livers were excised to measure GSH contents using Total Glutathione Quantification kit (Dojindo Molecular Technologies, Kumamoto, Japan) according to the manufacturer's instructions at 0,2 , and $4 \mathrm{~h}$ after APAP injection $(\mathrm{n}=10$ at each time point/group).

Biochemical analyses. Blood samples (200 $\mu 1$ at each time point) were taken from tail vein or inferior vena cava at 24 and $48 \mathrm{~h}$ after the injection of APAP ( $\mathrm{n}=10$ in each group).
Serum levels of alanine aminotransferase (AST), alanine aminotransferase (ALT), fibrin degradation products (FDP), and HMGB1 were estimated by Transaminase C-test (Wako Pure Chemical Industry, Osaka, Japan), FDP-ELISA kit (MyBioSource, San Diego, CA, USA), and HMGB1-ELISA kit (Shino-test, Japan). Serum levels of Total bilirubin (T.Bil) and lactate dehydrogenase ( $\mathrm{LDH})$ were measured using chemical analyzer Fuji-Drychem (Fuji Film, Tokyo, Japan). Platelet was counted using an automated hematology analyzer (Sysmex XE-5000 hematology analyzer; Sysmex, Kobe, Japan) in EDTA-anticoagulated blood samples. Prothrombin time (PT-INR) measurements were performed on venous blood sample drawn from the tail vein by a commercially available point-of-care coagulometer (CoaguChek XS; Roche, Mannheim, Germany).

Histological examinations. Liver tissue samples were collected at $24 \mathrm{~h}$ after APAP injection, fixed in $10 \%$ formalin, and embedded in paraffin ( $n=10 /$ group). Sections were stained with hematoxylin and eosin to assess hepatic damage. Sinusoidal fibrin deposition was detected by phosphotungstic acid-hematoxylin staining. The F4/80 immunohistochemical staining assays were performed. Paraffin-embedded tissue sections were deparaffinized and rehydrated. Antigen retrieval was performed with Proteinase K (Dako, Carpinteria, CA, USA) treatment. Endogenous peroxidase activity was blocked for 20 min with $3 \%$ hydrogen peroxide (Sigma-Aldrich, St. Louis, MO, USA). After blocking with diluted serum from the secondary antibody host for $30 \mathrm{~min}$, the slides were incubated overnight $\left(4^{\circ} \mathrm{C}\right)$ with anti-F4/80 antibody (Bio-Rad, Hercules, CA, USA; catalog no. MCA497; 1:1,000 dilution). Secondary anitibody (Histofine Simple Stain Mouse MAX-PO Rat kit; Nichirei Bioscience, Tokyo, Japan) was applied for $60 \mathrm{~min}$ at room temperature and stained for 1-10 min with diaminobenzidine tetrahydrochloride (Nichirei Bioscience). The sections were then counterstained with hematoxylin (Thermo Fisher Scientific, Inc., Waltham, MA, USA), dehydrated, and mounted. The sections were visualized under a Keyence BZ-X700 microscope (Keyence, Osaka, Japan) at different magnifications (x200 magnification, Fig. 1; x400 magnification, Fig. 2; and x200 magnification, Fig. 3).

Reverse transcription-quantitative polymerase chain reaction $(R T-q P C R)$. Total RNA from liver tissue was prepared with TRIzol reagent (Invitrogen; Thermo Fisher Scientific, Inc.) and cDNA was synthesized by GeneAmp RNA PCR (Applied Biosystems; Thermo Fisher Scientific, Inc.). RT-qPCR was performed using SYBR-Green on the ABI 7500 real-time PCR System (Applied Biosystems; Thermo Fisher Scientific, Inc.). The PCR reaction was carried out with a denaturation step at $95^{\circ} \mathrm{C}$ for $30 \mathrm{sec}$, then 40 cycles at $95^{\circ} \mathrm{C}$ for $5 \mathrm{sec}$ and finally at $60^{\circ} \mathrm{C}$ for $34 \mathrm{sec}$. To control for variations in the reactions, all data were normalized to GAPDH expression. Relative expression was presented using the $2^{-\Delta \Delta \mathrm{Cq}}$ method (37). The primer sequences are listed in Table I.

Statistical analysis. Data were analyzed using JMP Pro Version 11 statistical software (SAS Institute, Inc. Cary, NC, USA). The values of serum biomarkers (AST, ALT, LDH, T.Bil, FDP and HMGB1 ) and PT-INR were expressed as the means and standard deviation (SD). The results of hepatic 


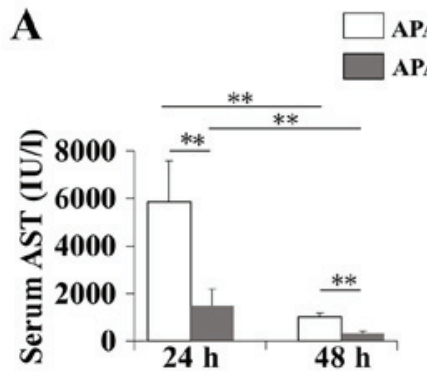

APAP

PAP+rhTM
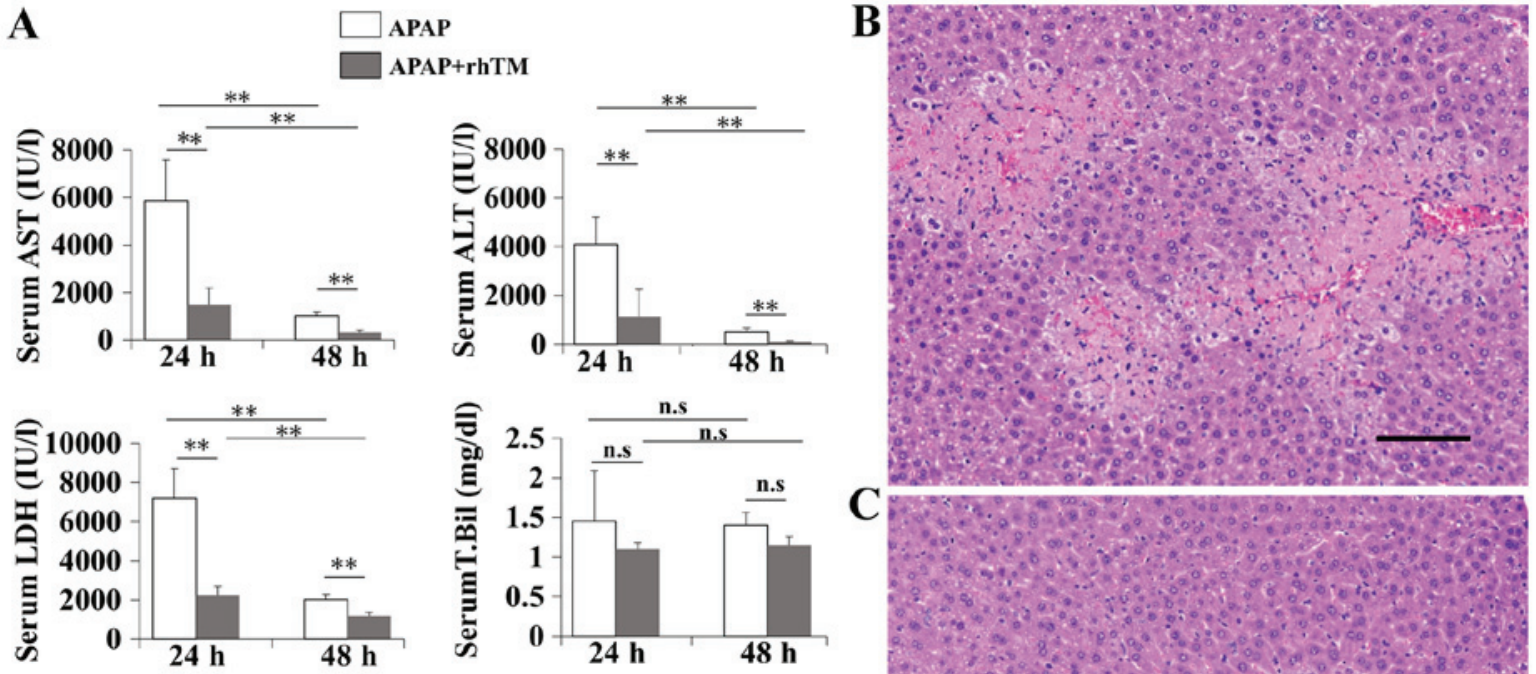

C

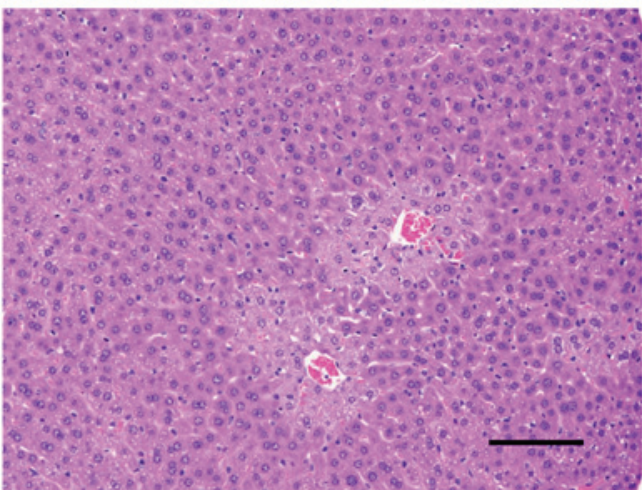

Figure 1. rhTM suppresses liver damage in a mouse AILI model. APAP was injected intraperitoneally into 8-week-old C57BL/6 mice. At the same time, rhTM (TM group) or saline (control group) was injected intraperitoneally. Biochemical examinations were performed at 24 and $48 \mathrm{~h}$ after APAP injection ( $\mathrm{n}=10$ in each group at each time point). Histological examinations (magnification, $\mathrm{x} 200$ ) were performed at $24 \mathrm{~h}$ after the injection ( $\mathrm{n}=10$ in each group). Scale bar $=100 \mu \mathrm{m}$. (A) Serum AST, ALT, LDH, T.Bil and PT-INR levels. Data are expressed as the mean \pm SD. ${ }^{* *} \mathrm{P}<0.01$. ns, non-significant. Hematoxylin and eosin staining of liver sections. (B) control group, (C) TM group. rhTM, recombinant human soluble thrombomodulin alpha; AILI, acetaminophen induced liver disease; APAP, acetaminophen; AST, alanine aminotransferase; ALT, alanine aminotransferase; LDH, lactate dehydrogenase; T.Bil, total bilirubin; PT-INR, prothrombin time.

A

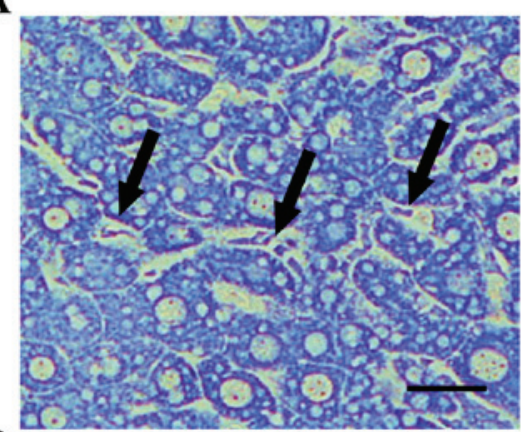

B

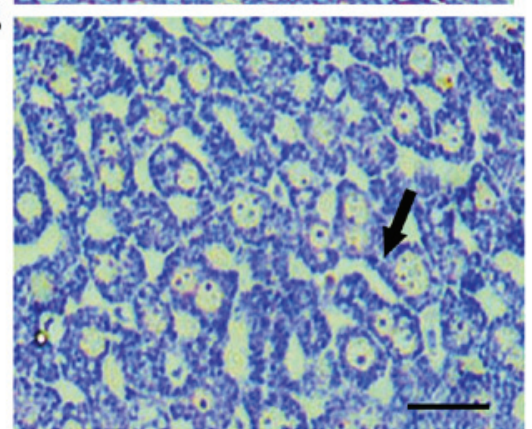

C

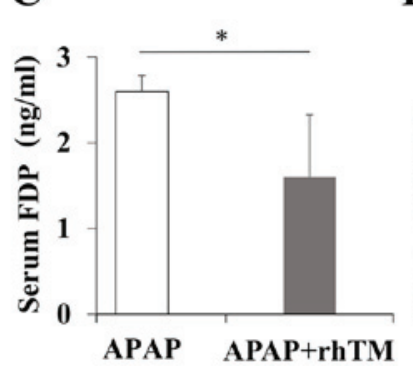

$\mathbf{E}$
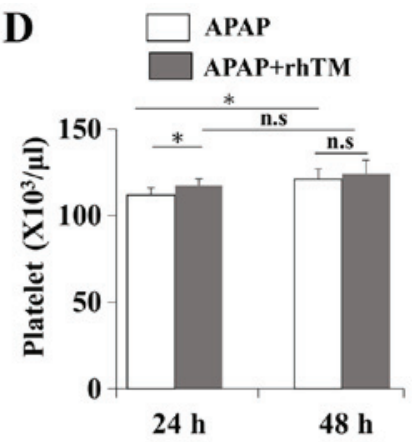

24 h

$48 \mathrm{~h}$

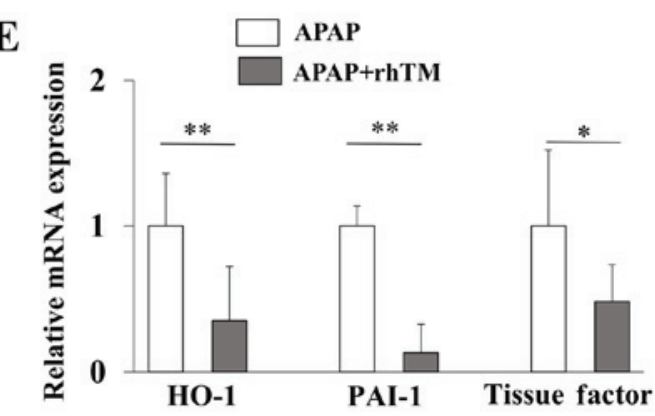

Figure 2. rhTM improves intrahepatic coagulopathy. Phosphotungstic acid-hematoxylin staining was performed to detect the sinusoidal fibrin deposition induced by sinusoidal coagulopathy (magnification, x400). (A) Control group. (B) TM group. The arrows indicate fibrin depositions in sinusoids. Scale bar $=25 \mu \mathrm{m}$ ). (C) Serum FDP levels were measured at $24 \mathrm{~h}$ after APAP injection. (D) Platelet counts were measured at 24 and $48 \mathrm{~h}$ after APAP injection ( $\mathrm{n}=10$ in each group at each time point). Data are expressed as the mean $\pm \mathrm{SD}$ ( $\mathrm{n}=10$ in each group). (E) Hepatic expression levels of HO-1, PAI-1 and TF were quantified by RT-qPCR. Data are expressed as the mean $\pm \mathrm{SEM}$ ( $\mathrm{n}=10$ in each group). ${ }^{*} \mathrm{P}<0.05,{ }^{* *} \mathrm{P}<0.01$. ns, non-significant. rhTM, recombinant human soluble thrombomodulin alpha; FDP, fibrin degradation products; APAP, acetaminophen; HO-1, heme oxygenase-1; PAI-1, plasminogen activator inhibitor type 1; TF, tissue factor. 

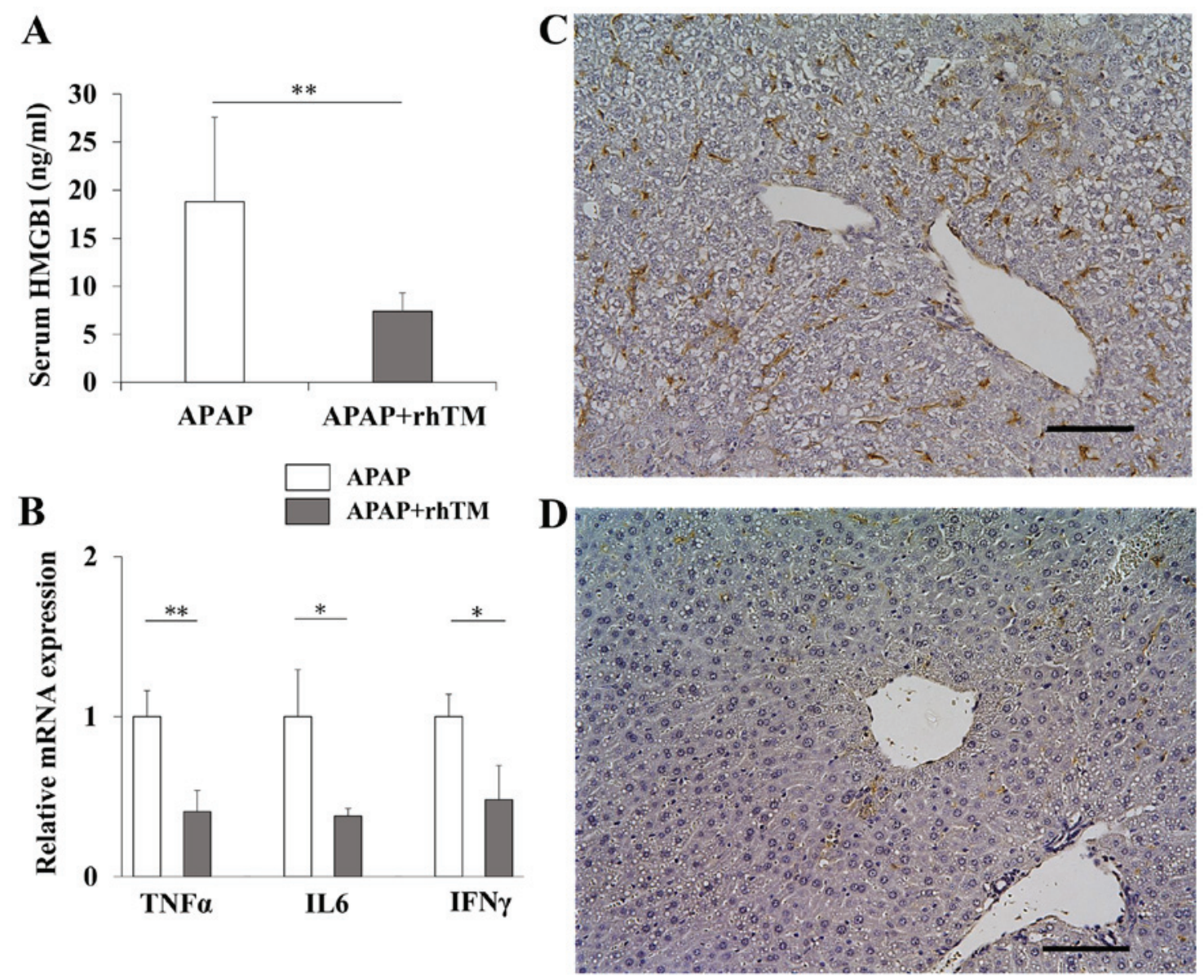

Figure 3. rhTM reduces HMGB1 and downregulates proinflammatory genes. (A) Serum HMGB1 levels were measured at $24 \mathrm{~h}$ after APAP injection. Data are expressed as the mean \pm SD ( $\mathrm{n}=10$ in each group). (B) Hepatic expression levels of TNF $\alpha$, IL6 and IFN $\gamma$ were quantified by RT-qPCR. Data are expressed as the mean \pm SEM ( $n=10$ in each group). ${ }^{*} \mathrm{P}<0.05,{ }^{* *} \mathrm{P}<0.01$ vs. control goup. Immunostaining of liver sections shows the infiltration of $\mathrm{F} 4 / 80$ positive macrophages (magnification, x200). Scale bar=100 $\mu \mathrm{m}$. (C) Control group. (D) TM group. rhTM, recombinant human soluble thrombomodulin alpha; HMGB1, high-mobility group box 1; APAP, acetaminophen; TNF $\alpha$, tumor necrosis factor $\alpha$; IL6, interleukin-6; IFN $\gamma$, interferon $\gamma$.

mRNA expression were expressed as standard error of the means (SEM). Significant differences between two groups were assessed using the Mann-Whitney U-test. The differnces of means among multiple groups were analyzed by using one-way ANOVA and Tukey's post hoc test. A P-value $<0.05$ indicated statistical significance.

\section{Results}

rhTM attenuates APAP induced hepatotoxicity in mice. In preliminary experiment, we used $500 \mathrm{mg} / \mathrm{kg}$ of APAP to induce AILI, but rhTM did not affect liver damages (data not shown). Then we reduced APAP to $200 \mathrm{mg} / \mathrm{kg}$ and carried out the following experiments. Elevated serum liver transaminases in the control group indicated successful induction of AILI. Administration of rhTM significantly decreased serum AST, ALT, and LDH compared to those in the control group and this suppressive effect of rhTM on liver damage continued for $48 \mathrm{~h}$ (Fig. 1A). We also evaluated serum levels of T.Bil and PT-INR. The value remained in mostly normal range and rhTM did not significantly affect the both levels of T.Bil (control group vs TM group: $1.4 \pm 0.6$ vs. $1.1 \pm 0.1 \mathrm{mg} / \mathrm{dl}, \mathrm{P}=0.37$ ) and PT-INR (control group vs. TM group: $1.2 \pm 0.1$ vs. $1.1 \pm 0.2 \mathrm{mg} / \mathrm{dl}, \mathrm{P}=0.82$ ) at $24 \mathrm{~h}$ after APAP injection (Fig. 1A). T.Bil and PT-INR are recognized as useful markers to speculate the prognosis of liver failure patients (38). However, elevations of theses factors have not been obviously shown in APAP-induced ALF model mice $(39,40)$, suggesting that the experimental doses of APAP may not disrupt these values. Histological examination showed extensive hepatocellular necrosis and hemorrhage with modest infiltration of inflammatory cells in the control group (Fig. 1B) and rhTM markedly reduced the necrotic area and diminished the intralobular hemorrhage at $24 \mathrm{~h}$ after APAP injection (Fig. 1C). Previously, rhTM has been reported to exert its anticoagulant and anti-inflammatory activity at a dose of $1-200 \mathrm{mg} / \mathrm{kg}$ (32-35). In preliminary experiments, we evaluated the effects of rhTM on APAP-induced liver injury at a dose of $10 \mathrm{mg} / \mathrm{ml}$, however, rhTM in this dose did not show significant suppression of liver damages (data not shown). Then we tried rhTM at a dose of $20 \mathrm{mg} / \mathrm{ml}$ and significant improving effects of rhTM in this dose allowed us to continue to investigate this study. It is unclear why higher dose was required in this study, however, we speculate that the difference of animal models may affect the appropriate dose for treatment.

rhTM improves intrahepatic coagulopathy. Diffuse distribution of sinusoidal fibrin depositions was observed in control liver and rhTM treatment mostly extinguished the depositions 
Table I. qPCR primer sequence.

\begin{tabular}{ll}
\hline Gene & \multicolumn{1}{c}{ Primer sequences (5'-3') } \\
\hline TNF $\alpha$ & F: TATGGCTCAGGGTCCAACTC \\
& R: CTCCCTTTGCAGAACTCAGG \\
IL6 & F: AGTTGCCTTCTTGGGACTGA \\
& R: TCCACGATTTCCCAGAGAAC \\
IFN $\gamma$ & F: ACTGGCAAAAGGATGGTGAC \\
& R: TGAGCTCATTGAATGCTTGG \\
HO-1 & F: ACGCATATACCCGCTACCTG \\
& R: AAGGCGGTCTTAGCCTCTTC \\
PAI-1 & F: TCTGGGAAAGGGTTCACTTTACC \\
& F: TGCTTCTCGACCACAGACAC \\
TF & R: TAAAAACTTTGGGGCGTTTG
\end{tabular}

TNF $\alpha$, tumor necrosis factor $\alpha$; IL6, interleukin6; IFN $\gamma$, interferon $\gamma$; HO-1, heme oxygenase -1; PAI-1, plasminogen activator inhibitor-1; $\mathrm{TF}$, tissue factor.

(Fig. 2A and B). Then we evaluated serum FDP levels. In ALF patients, serum FDP was occasionally found elevated and considered to be useful to speculate the extent of complicated coagulopathy (8). As shown in Fig. 2C, rhTM significantly reduced serum FDP compared with control group at $24 \mathrm{~h}$ after APAP injection. Hemostatic alterations in liver disease with intrahepatic coagulopathy occasionally reduces the platelet counts (41). rhTM improved platelet counts at $24 \mathrm{~h}$ after APAP injection in TM group (117.3 \pm 4.0 vs. control group: $111.7 \pm 4.3 \times 10^{4} / \mu 1, \mathrm{P}<0.05$ Fig. $\left.2 \mathrm{D}\right)$. In addition, rhTM treatment significantly reduced the hepatic expressions of heme oxygenase-1 (HO-1), plasminogen activator inhibitor type 1 (PAI-1) and tissue factor (TF), suggesting that rhTM suppressed the further exacerbation of hepatic hyper-coagulation (Fig. 2E).

rhTM treatment suppresses inflammatory reactions. As shown in Fig. 3A, serum HMGB1 in the TM group was significantly lower than those in the control group. To evaluate the induction of proinflammatory activity, we quantified mRNA expressions of TNF $\alpha$, IL6, and IFN $\gamma$. rhTM treatment significantly reduced the expressions of all these genes (Fig. 3B). We also estimated hepatic macrophage accumulation by F4/80 immunostaining. In APAP hepatotoxicity, resident hepatic macrophage, Kupffer cell, and bone-marrow derived monocytes are activated to aggravate inflammation and monocyte derived macrophage (MoMF) is involved in the resolution of inflammation $(42,43)$. As shown in Fig. 3C, F4/80 immunostaining showed the abundant hepatic infiltration of macrophages in control group, but mostly disappeared in TM group (Fig. 3D).

Temporal changes in liver GSH contents. The APAP metabolite NAPQI induces hepatic GSH depletion, resulting in hepatocyte necrosis (25). To evaluate the effect of rhTM on the direct hepatotoxicity, we evaluated hepatic GSH contents. At $2 \mathrm{~h}$ after APAP injection, hepatic GSH levels were equally decreased in both groups (Fig. 4). At $4 \mathrm{~h}$ after APAP injection, GSH contents in the TM group rose again

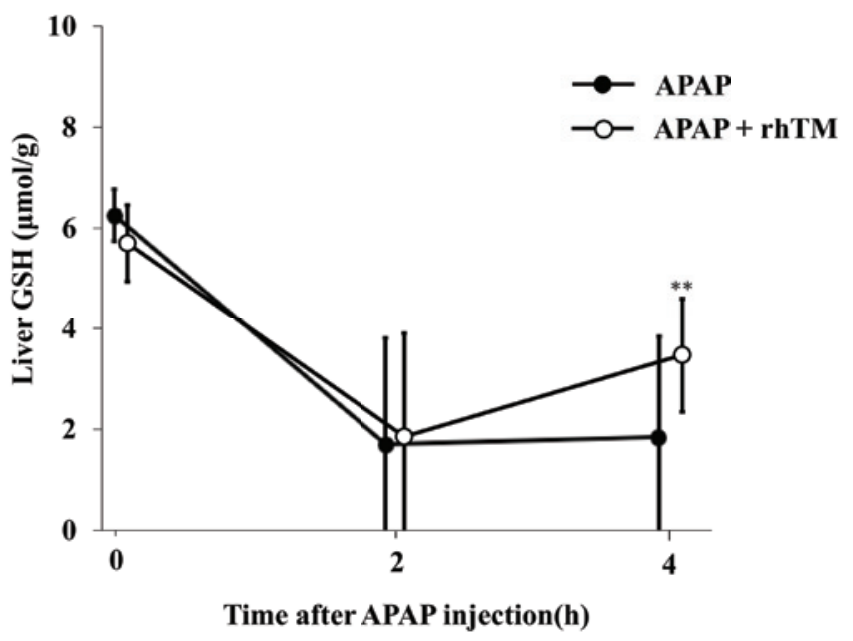

Figure 4. rhTM restores hepatic GSH contents. The liver tissue samples were collected at 0,2 , and $4 \mathrm{~h}$ after APAP injection and hepatic GSH contents were evaluated. GSH levels at $2 \mathrm{~h}$ after APAP injection were significantly decreased in both groups compared with the levels at $0 \mathrm{~h}$ $(\mathrm{P}<0.01)$. At $4 \mathrm{~h}$ after APAP injection, GSH contents in the control group were not changed but those in the TM treated group (APAP + rhTM group) significantly increased compared to those in the control group (APAP group). Data are expressed as the mean \pm SD ( $n=10$ in each group at each time point). ${ }^{* *} \mathrm{P}<0.01$ vs. control group (APAP group). rhTM, recombinant human soluble thrombomodulin $\alpha$; GSH, glutathione; APAP, acetaminophen.

with a significant difference compared to those in the control group.

\section{Discussion}

The mechanism of APAP induced hepatotoxity involves a oxidative stress and mitochondrial dysfunction via its metabolite NAPQI $(13,15,25)$. In addition, recent studies indicated that APAP hepatotoxity is accompanied by inflammation response $(44,45)$. Mediators released from necrotic hepatocyte stimulate Kupffer cell and sinusoidal endothelial cell. These mediators activate hepatic hyper-coagulation including fibrin deposition and exacerbate liver injury in AILI (22). In clinical cases, the characteristic finding in patients with AILI is the distinct elevation of serum lactate dehydrogenase similar to hypoxic hepatitis, suggesting that the liver could be in hypoxic state associated with hepatic microcirculatory perfusion failure (46).

Here, we showed that rhTM ameliorated APAP induced liver damage in mice. rhTM suppressed serum ALT elevation and reduced liver cell necrosis with decreased sinusoidal fibrin deposition, probably induced by preserved liver perfusion.

In preliminary experiment, we used $500 \mathrm{mg} / \mathrm{kg}$ of APAP to induce hepatotoxicity and rhTM did not fully suppress liver damages. Then we reduced APAP into $200 \mathrm{mg} / \mathrm{kg}$ and rhTM significantly improved liver damages. We speculate that the inefficiency of rhTM on mice injected with $500 \mathrm{mg} / \mathrm{kg}$ of APAP might be attributable to the strong direct hepatocyte necrosis proceeded independently of hepatic hyper-coagulation and inflammation. The involvement of inflammatory cell activations has been reported in AILI (43), liver injury induced by high-dose APAP $(400 \mathrm{mg} / \mathrm{kg})$ could not be attenuated in TNF/lymphotoxin-alpha knock out mice (47). The inefficiency 
of blunting TNF signaling suggests that the inflammatory reaction seems to be unnecessary in cell death in high-dose APAP. Treating hepatic hyper-coagulation seems ineffective to suppress liver cell necrosis in high-dose APAP induced liver damage.

In this study, treatment with rhTM was accompanied with reduced sinusoidal fibrin deposition. Not only a result of hemostatic disturbance, fibrin deposition may be a causal player in acute liver injury (48). Fibrin could be deposited as intravascular microthrombi, leading to obstruct local liver perfusion, resulting in the secondary enhanced liver injury. Thus, anticoagulants have been tried to diminish tissue damages in various types of liver injury (11,49-51). In AILI, pretreatment of heparin significantly attenuated liver injury with diminished fibrin deposition (22). Collectively, we speculate that rhTM might suppress liver damage via preserved liver perfusion by the improvement in hepatic hyper-coagulation. The changes in liver GSH contents may support this idea. We observed that liver GSH in the TM group reduced equally at $2 \mathrm{~h}$ after APAP injection but rose again with a significant difference at $4 \mathrm{~h}$ compared to those in the control group. The reduction of GSH in the early stage suggests that rhTM could not interfere the production of harmful metabolite. Restoration of GSH contents at $4 \mathrm{~h}$ suggests that the preserved liver perfusion might supply GSH to injured hepatocytes, preventing further expansion of necrosis.

The role of rhTM in the prevention of secondary liver damage is also suggested by the downregulations of hepatic hyper-coagulation and inflammation related genes. HO-1 has been shown as an important component of antioxidant defense in APAP hepatotoxicity (52). PAI-1 and TF released from damaged cells exacerbate coagulopathy by inhibiting the anticoagulative cascades (53-55). Thus the downregulations of PAI-1 and TF suggest that the preservation of liver perfusion by rhTM improved the redox state in diseased liver, thereby prevented secondary coagulopathy induced by damaged tissue. In similar fashion, preserved liver perfusion by rhTM likely reduced the release of damage-associated molecular patterns (DAMPs), followed by the downregulations of proinflammatory cytokines, resulting in the prevention of secondary damages.

In the present study, the administration of rhTM effectively suppressed liver damage in the APAP-induced ALF model, probably by improving the intrahepatic coagulopathy. Because the improving effects of rhTM on liver damage could be observed in low-dose APAP intoxication, the utility of rhTM in AILI might be limited. Treatment with NAC should be considered primarily, however, rhTM might be useful to support the treatment in cases with hepatic hyper-coagulation. Also, this study has a limitation because the improving effects of rhTM on liver injury were shown when rhTM was injected at the same time of APAP intoxication, which unlikely happens in clinical situations. In addition, as an anticoagulant, rhTM is known to increase the risk of bleeding. We did not experience hemorrhagic complications in this study, however, intensive attention for such adverse effects is necessary in the cases with ALF. The involvement of anti-inflammatory activity of rhTM in the suppression of AILI is still unclear, further study would be helpful to understand the role of rhTM in the suppression of AILI.

\section{Acknowledgements}

The authors would like to acknowledge the technical assistance from The Research Support Center, Kyushu University Graduate School of Medical Sciences. The authors would also like to thank J. Ludovic Croxford, from the Edanz Group (www. edanzediting.com/ac) for editing a draft of this manuscript.

\section{Funding}

This study was supported in part by the Takeda Science Foundation.

\section{Availability of data and materials}

The dataset used and/or analyzed during the current study are available from the corresponding author on reasonable request.

\section{Authors' contributions}

AK, MKo, MKa and YO designed the study. AK performed experiments. HS, AY, TO, KI, MKu and YM assisted experiments and data analyses. AK wrote the initial draft of the manuscript. MKo, MKa and YO contributed to analysis and interpretation of data. MKo, MKa and $\mathrm{YO}$ assisted in the preparation of the manuscript and critically reviewed the manuscript. All authors approved the final version of the manuscript and agreed to be accountable for all aspects of the work.

\section{Ethics approval and consent to participate}

The present study was performed in accordance with the Guide for the Care and Use of Laboratory Animals (National Institutes of Health) and approved by the Animal Care Committee of Kyushu University.

\section{Patient consent for publication}

Not applicable.

\section{Competing interests}

The authors declare that they have no competing interests.

\section{References}

1. Fujiwara K, Mochida S, Matsui A, Nakayama N, Nagoshi S and Toda G; Intractable Liver Diseases Study Group of Japan: Fulminant hepatitis and late onset hepatic failure in Japan. Hepatol Res 38: 646-657, 2008.

2. Starzl TE, Iwatsuki S, Van Thiel DH, Gartner JC, Zitelli BJ, Malatack JJ, Schade RR, Shaw BW Jr, Hakala TR, Rosenthal JT and Porter KA: Evolution of liver transplantation. Hepatology 2: 614-636, 1982.

3. Polson J and Lee WM; American Association for the Study of Liver Disease: AASLD position paper: The management of acute liver failure. Hepatology 41: 1179-1197, 2005.

4. Mochida $\mathrm{S}$ and Fujiwara K: Symposium on clinical aspects in hepatitis virus infection. 2. Recent advances in acute and fulminant hepatitis in Japan. Intern Med 40: 175-177, 2001.

5. Vollmar B, Glasz J, Leiderer R, Post S and Menger MD: Hepatic microcirculatory perfusion failure is a determinant of liver dysfunction in warm ischemia-reperfusion. Am J Pathol 145: 1421-1431, 1994. 
6. Hillenbrand P, Parbhoo SP, Jedrychowski A and Sherlock S: Significance of intravascular coagulation and fibrinolysis in acute hepatic failure. Gut 15: 83-88, 1974.

7. Kotoh K, Kato M, Kohjima M, Tanaka M, Miyazaki M, Nakamura K, Enjoji M, Nakamuta $M$ and Takayanagi R: Lactate dehydrogenase production in hepatocytes is increased at an early stage of acute liver failure. Exp Ther Med 2: 195-199, 2011.

8. Hirata K, Ogata I, Ohta Y and Fujiwara K: Hepatic sinusoidal cell destruction in the development of intravascular coagulation in acute liver failure of rats. J Pathol 158: 157-165, 1989.

9. Mochida S, Arai M, Ohno A, Yamanobe F, Ishikawa K, Matsui A, Maruyama I, Kato H and Fujiwara K: Deranged blood coagulation equilibrium as a factor of massive liver necrosis following endotoxin administration in partially hepatectomized rats. Hepatology 29: 1532-1540, 1999.

10. Miyazaki M, Kato M, Tanaka K, Tanaka M, Takao S, Kohjima M, Enjoji M, Nakamuta M, Kotoh K and Takayanagi R: Contrast-enhanced ultrasonography using Sonazoid to evaluate changes in hepatic hemodynamics in acute liver injury. J Gastroenterol Hepatol 26: 1749-1756, 2100.

11. Miyazaki M, Kato M, Tanaka K, Tanaka M, Takao S, Kohjima M, Ito T, Enjoji M, Nakamuta M, Kotoh $\mathrm{K}$ and Takayanagi R: Antithrombin III injection via the portal vein suppresses liver damage. World J Gastroenterol 18: 1884-1891, 2012.

12. Fujiwara K, Okita K, Akamatsu K, Abe H, Tameda Y, Sakai T, Inoue N, Kanai K, Aoki N and Oka H: Antithrombin III concentrate in the treatment of fulminant hepatic failure. Gastroentero Jpn 23: 423-427, 1988

13. Graham GG, Scott KF and Day RO: Tolerability of paracetamol. Drug Saf 28: 227-240, 2005.

14. Li C and Martin BC: Trends in emergency department visits attributable to acetaminophen overdoses in the United States: 1993-2007. Pharmacoepidemiol Drug Saf 20: 810-818, 2011.

15. Jaeschke H and McGill MR: Cytochrome P450-derived versus mitochondrial oxidant stress in acetaminophen hepatotoxicity. Toxicol Lett 235: 216-217, 2015.

16. Han D, Dara L, Win S, Than TA, Yuan L, Abbasi SQ, Liu ZX and Kaplowitz N: Regulation of drug-induced liver injury by signal transduction pathways: Critical role of mitochondria. Trends Pharmacol Sci 34: 243-253, 2013.

17. James LP, McCullough SS, Lamps LW and Hinson JA: Effect of $\mathrm{N}$-acetylcysteine on acetaminophen toxicity in mice: Relationship to reactive nitrogen and cytokine formation. Toxicol Sci 75: 458-467, 2003

18. Smilkstein MJ, Knapp GL, Kulig KW and Rumack BH: Efficacy of oral $\mathrm{N}$-acetylcysteine in the treatment of acetaminophen overdose. Analysis of the national multicenter study (1976 to 1985). N Engl J Med 319: 1557-1562, 1988.

19. Koch DG, Speiser JL, Durkalski V, Fontana RJ, Davern T, McGuire B, Stravitz RT, Larson AM, Liou I, Fix O, et al: The natural history of severe acute liver injury. Am J Gastroenterol 112: 1389-1396, 2017.

20. Michael Brown J, Ball JG, Wright MS, Van Meter S and Valentovic MA: Novel protective mechanisms for S-adenosyl-L-methionine against acetaminophen hepatotoxicity: Improvement of key antioxidant enzymatic function. Toxicol Lett 212: 320-328, 2012.

21. James LP, Wells E, Beard RH and Farrar HC: Predictors of outcome after acetaminophen poisoning in children and adolescents. J Pediatr 140: 522-526, 2002.

22. Ganey PE, Luyendyk JP, Newport SW, Eagle TM, Maddox JF, Mackman N and Roth RA: Role of the coagulation system in acetaminophen-induced hepatotoxicity in mice. Hepatology 46 : 1177-1186, 2007.

23. Esmon CT: The interactions between inflammation and coagulation. Br J Haematol 131: 417-430, 2005.

24. Ikezoe T: Thrombomodulin/activated protein $\mathrm{C}$ system in septic disseminated intravascular coagulation. J Intensive Care 3: 1, 2015

25. Du K, Ramachandran A and Jaeschke H: Oxidative stress during acetaminophen hepatotoxicity: Sources, pathophysiological role and therapeutic potential. Redox Biol 10: 148-156, 2016.

26. Chen R, Hou W, Zhang Q, Kang R, Fan XG and Tang D: Emerging role of high-mobility group box 1 (HMGB1) in liver diseases. Mol Med 19: 357-366, 2013

27. Okamoto T, Tanigami H, Suzuki K and Shimaoka $M$ : Thrombomodulin: A bifunctional modulator of inflammation and coagulation in sepsis. Crit Care Res Pract 2012: 614545, 2012.

28. Li YH, Kuo CH, Shi GY and Wu HL: The role of thrombomodulin lectin-like domain in inflammation. J Biomed Sci 19: 34, 2012.
29. Ikezoe T: Pathogenesis of disseminated intravascular coagulation in patients with acute promyelocytic leukemia, and its treatment using recombinant human soluble thrombomodulin. Int J Hematol 100: 27-37, 2014.

30. Eguchi Y, Gando S, Ishikura H, Saitoh D, Mimuro J, Takahashi H, Kitajima I, Tsuji H, Matsushita T, Tsujita R, et al: Post-marketing surveillance data of thrombomodulin alfa: Sub-analysis in patients with sepsis-induced disseminated intravascular coagulation. J Intensive Care 2: 30, 2014

31. Osumi W, Jin D, Imai Y, Tashiro K, Li ZL, Otsuki Y, Maemura K, Komeda K, Hirokawa F, Hayashi M, et al: Recombinant human soluble thrombomodulin improved lipopolysaccharide/d-galactosamine-induced acute liver failure in mice. J Pharmacol Sci 129: 233-239, 2015.

32. Hagiwara S, Iwasaka H, Matsumoto S, Hasegawa A, Yasuda N and Noguchi T: In vivo and in vitro effects of the anticoagulant, thrombomodulin, on the inflammatory response in rodent models. Shock 33: 282-288, 2010.

33. Nakamura K, Hatano E, Miyagawa-Hayashino A, Okuno M, Koyama Y, Narita M, Seo S, Taura K and Uemoto S: Soluble thrombomodulin attenuates sinusoidal obstruction syndrome in rat through suppression of high mobility group box 1 . Liver Int 34: 1473-1487, 2014

34. Kawasaki T, Okamoto $\mathrm{K}$, Kawasaki $\mathrm{C}$ and Sata T: Thrombomodulin improved liver injury, coagulopathy, and mortality in an experimental heatstroke model in mice. Anesth Analg 118: 956-963, 2014.

35. Soto-Montenegro ML, Vicente-Rodríguez M, Pérez-García C, Gramage E, Desco M and Herradón G: Functional neuroimaging of amphetamine-induced striatal neurotoxicity in the pleiotrophin knockout mouse model. Neurosci Lett 591: 132-137, 2015.

36. Mortensen MB, Nilsson L, Larsen TG, Espeseth E, Bek M, Bjorklund MM, Hagensen MK, Wolff A, Gunnersen S, Füchtbauer EM, et al: Prior renovascular hypertension does not predispose to atherosclerosis in mice. Atherosclerosis 249: 157-163, 2016.

37. Livak KJ and Schmittgen TD. Analysis of relative gene expression data using real-time quantitative PCR and the $2-\Delta \Delta \mathrm{Ct}$ method. Methods 25: 402-408 2001.

38. Zaman MB, Hoti E, Qasim A, Maguire D, McCormick PA, Hegarty JE, Geoghegan JG and Traynor O: MELD score as a prognostic model for listing acute liver failure patients for liver transplantation. Transplant Proc 38: 2097-2098, 2006.

39. Mahrous Abdel Basset Ibrahim, Farooq Ahmed Wani and Shaik Rahiman: Hepatoprotective effect of olive oil and camel milk on acetaminophen-induced liver toxicity in mice. Int J Med Sci Public Health 6: 186-194, 2017.

40. Saini SP, Zhang B, Niu Y, Jiang M, Gao J, Zhai Y, Hoon Lee J, Uppal H, Tian H, Tortorici MA, et al: Activation of liver X receptor increases acetaminophen clearance and prevents its toxicity in mice. Hepatology 54: 2208-2217.

41. Lisman T and Porte RJ: Rebalanced hemostasis in patients with liver disease: Evidence and clinical consequences. Blood 116: 878-185, 2010.

42. Choi DY, Ban JO, Kim SC and Hong JT: CCR5 knockout mice with C57BL6 background are resistant to acetaminophen-mediated hepatotoxicity due to decreased macrophages migration into the liver. Arch Toxicol 89: 211-220, 2015.

43. Krenkel O, Mossanen JC and Tacke F: Immune mechanisms in acetaminophen-induced acute liver failure. Hepatobiliary Surg Nutr 3: 331-343, 2014

44. Williams CD, Farhood A and Jaeschke H: Role of caspase-1 and interleukin-1beta in acetaminophen-induced hepatic inflammation and liver injury. Toxicol Appl Pharmacol 247: 169-178, 2010.

45. Maddox JF, Amuzie CJ, Li M, Newport SW, Sparkenbaugh E, Cuff CF, Pestka JJ, Cantor GH, Roth RA and Ganey PE: Bacterial- and viral-induced inflammation increases sensitivity to acetaminophen hepatotoxicity. J Toxicol Environ Health A 73: 58-73, 2010 .

46. Cassidy WM and Reynolds TB: Serum lactic dehydrogenase in the differential diagnosis of acute hepatocellular injury. J Clin Gastroenterol 19: 118-121, 1994.

47. Boess F, Bopst M, Althaus R, Polsky S, Cohen SD, Eugster HP and Boelsterli UA: Acetaminophen hepatotoxicity in tumor necrosis factor/lymphotoxin-alpha gene knockout mice. Hepatology 27: 1021-1029, 1998

48. Kopec AK and Luyendyk JP: Role of fibrin (ogen) in progression of liver disease: Guilt by association? Semin Thromb Hemost 42: 397-407, 2016 
49. Weerasinghe SV, Moons DS, Altshuler PJ, Shah YM and Omary MB: Fibrinogen- $\gamma$ proteolysis and solubility dynamics during apoptotic mouse liver injury: Heparin prevents and treats liver damage. Hepatology 53: 1323-1332, 2011.

50. Nagato M, Okamoto K, Abe Y, Higure A and Yamaguchi K: Recombinant human soluble thrombomodulin decreases the plasma high-mobility group box-1 protein levels, whereas improving the acute liver injury and survival rates in experimental endotoxemia. Crit Care Med 37: 2181-2186, 2009.

51. Fujiwara K, Ogata I, Ohta Y, Hirata K, Oka Y, Yamada S, Sato $\mathrm{Y}$, Masaki $\mathrm{N}$ and Oka $\mathrm{H}$ : Intravascular coagulation in acute liver failure in rats and its treatment with antithrombin III. Gut 29: 1103-1108, 1988.

52. Chiu H, Brittingham JA and Laskin DL: Differential induction of heme oxygenase-1 in macrophages and hepatocytes during acetaminophen-induced hepatotoxicity in the rat: Effects of hemin and biliverdin. Toxicol Appl Pharmacol 181: 106-115, 2002.
53. van der Poll T, Büller HR, ten Cate H, Wortel CH, Bauer KA, van Deventer SJ, Hack CE, Sauerwein HP, Rosenberg RD and ten Cate JW: Activation of coagulation after administration of tumor necrosis factor to normal subjects. N Engl J Med 322: 1622-1627, 1990

54. Sawdey MS and Loskutoff DJ: Regulation of murine type 1 plasminogen activator inhibitor gene expression in vivo. J Clin Investig 88: 1346-1353, 1991.

55. Li W, Chen W, Xie M, Huang H, Su H, Han H, Zhang D, Zhang Y, Yang $\mathrm{X}$ and $\mathrm{Xu} \mathrm{W}$ : Fasudil inhibits tissue factor and plasminogen activator inhibitor-1 secretion by peripheral blood mononuclear cells in CAPD patients. Ren Fail 38: 1359-1363, 2016. 